\title{
Demand Calculation Method for Electric Vehicle Charging Station Locating and Deployment
}

\author{
Csaba Csiszár ${ }^{*}$ \\ 1 Department of Transport Technology and Economics (KUKG), \\ Faculty of Transportation Engineering and Vehicle Engineering $(\mathrm{KJK})$, \\ Budapest University of Technology and Economics (BME), \\ H-1111 Budapest, Múegyetem rkp. 3, Hungary \\ *Corresponding author, e-mail: csiszar.csaba@mail.bme.hu
}

Received: 19 October 2018, Accepted: 11 January 2019, Published online: 30 January 2019

\begin{abstract}
To develop, plan, implement and operate the electric road mobility system, especially the charging infrastructure, the existing and potential demand must be revealed for several time horizons. Accordingly, the aim of the research was to elaborate a calculation method for electric vehicle charging demand and to determine the public charging infrastructure locating principles. The research questions were: how many and what kind of vehicles will be used; where, when and how long they will be charged; what aspects and how influence the charging station deployment. The number of charging points to be installed, the energy demand and capacity management parameters can be also determined using the revealed correlations. The calculation method is adaptable to any territorial unit and any time horizon. It is the basis of charging station locating methods, which is demonstrated through two novel geoinformatics applications.
\end{abstract}

\section{Keywords}

charging demand, charging infrastructure, deployment, electric vehicle, energy demand, geoinformatics, heterogeneous data, land use approach, point-oriented approach

\section{Introduction}

The transport sector has a significant impact on greenhouse gas (GHG) emission [1]. On the EU level, large efforts have been made to reduce the $\mathrm{CO}_{2}$ emission [2]. A roadmap for the transport sector to achieve a $60 \%$ reduction in its GHG emission level (compared with those of 1990) by 2050 has been outlined in the 2011 Transport White Paper [3]. Halving the use of conventionally fueled cars in urban transport by 2030 and phasing them out entirely in cities by 2050 is proposed.

The spread of electric vehicles (EVs) was proposed as a promising solution to reduce the emission of transport [4]. As a result of developments in recent years, the technology of EVs has become market-ready; several battery electric, hybrid, plug-in hybrid and range-extended vehicle types (BEV, HEV, PHEV and REEV) are available for customers. This evolvement process complemented by automation generates new challenges for the researchers $[5,6,7]$, because the entire road transportation alters, and technological development requires methodological advancement [8].
In this article, a novel calculation method of charging demand for locating and deployment of stations is presented. The method is to be applied in specifying the number and optimal allocation of charging network elements and calculating energy demand. In the next section, the literature review is provided. The review is compiled considering the factors influencing charging demand. In section 3 , these factors are summarized, and the most relevant findings of my questionnaire survey are discussed. The survey has been carried out to assess the expectations of current and potential EV users. Next, the elaborated method is presented in section 4. The identified relevant 'components' of the charging demand can be calculated according to the modules. The applicability of the method has been demonstrated in section 5 . In section 6 , the charging infrastructure locating principles are summarized. Then, novel geoinformatics methods and applications based on the principles and the developed calculation method are presented in section 7. Finally, the concluding remarks are provided. 


\section{Literature review}

The number of sold electric cars (including both BEVs and PHEVs) in one year increased by $70 \%$ between 2014 and 2015 [9]. The wider spread is facilitated by governmental incentives and purchase subsidies in several countries [10].

The technological drawbacks (limited range, relatively long charging times), high purchase price (with long payback time) and lack of system integration (limited public charging infrastructure, non-standardized charging methods) have been identified as main barriers for EVs $[11,12]$. Large efforts are made to study new technologies [13, 14], such as high energy battery cells. For example, the energy-density of PHEV batteries has been improved by almost $400 \%$ between 2008 and 2015 (from $60 \mathrm{Wh} / \mathrm{L}$ to $295 \mathrm{Wh} / \mathrm{L}$ ) that enabled improved $\mathrm{EV}$ ranges.

Despite higher investment costs, EVs can pay off $[15,16$, 17] and the payback period became shorter because of better market conditions and subsidies [18]. By 2030, long range electric mobility becomes feasible for many BEV categories; while in 2050, the cost-optimal powertrain concept will be the full electric for all vehicle categories. These results indicate that the financial drawbacks (high purchase price) of electromobility begin to decline, even though authors emphasize the importance of financial incentives at the same time.

The transportation demand can be forecasted by wellfounded models; however, several improvements are still possible, and the models are to be customized according to the local specialties [19] and available data sources. In many cases, modular solutions are established and applied [20] as data reliability varies according to the sources.

The charging demand is highly correlated to transportation demand; it is calculated, in the most cases, in connection with the charging station deployment. Albeit, relatively few EVs have been sold in Europe so far, charging infrastructure developments are accelerated in the last years. The first country which has completed the deployment of a nationwide electric car charging network was Estonia [21]. Nevertheless, only half of the drivers are satisfied with this charging network [22].

The optimal location, size and usage of charging network in Firenze has been deduced from the local consumer demand [23]. The expected size of the electric vehicle-fleet has been forecasted based on current, conventional vehicle usage patterns. Because of the need of domain-specific measurement data, implementation of this method is rather difficult. Similar approach has been applied in Beijing city $[24,25]$, where the locations for charging stations have been determined based on trajectory data of taxis.
The urban charging demand can be also deduced from several demographic and macroeconomic data (age, household income, residence type, commuting pattern, etc.), which characterize the potential vehicle buyers and influence the acceptance of EVs [26]. Xi et al. [27] introduced the term 'EV adoption probability' as a function of household demographic and macroeconomic variables. Charging demand, charger locations and expected charging capacity have been determined according to this probability.

Sathaye and Kelley [28] predicted the charging demand based on traffic and population characteristics as well as information about trip generation facilities. Charging demand of a geographical unit has been investigated based on the completed charging sessions in the research of Xydas et al. [29]. Their model was developed only to describe the current charging demand, and not to estimate future needs.

It can be confirmed according to the literature review that a system-oriented model for estimating future charging demand has not been developed yet. Identifying this research niche, a comprehensive calculation method has been elaborated.

\section{Factors influencing charging demand and user requirements}

The following main factor groups (Fi) that influence charging demand are identified:

$F_{1}$ technology and characteristics of vehicles;

$F_{2}$ charging technology and infrastructure;

$F_{3}$ governmental incentives (subsidies).

\subsection{Factors}

Improvements in vehicle and charging technology interact. The factors in the groups have been identified and then the time horizon of their impacts is estimated. The revealed correspondences are summarized in Table 1.

Governmental incentives affect the spread of electromobility, especially in the short term. Therefore, they play a key role in the early phase. Determination of longterm impacts and trends are rather difficult as innovative technologies (inductive charging, increased capacity and energy efficiency, smart grid solutions etc.) being under development may significantly change the operational characteristics and opportunities in the future.

EVs have a shorter range compared to the conventional vehicles with internal combustion engine, which might be further limited by adverse weather conditions or using comfort equipment (e.g. air conditioning system) [30]. The 
Table 1 Factors and time horizon of their impact

\begin{tabular}{|c|c|c|c|c|c|}
\hline \multirow{2}{*}{ 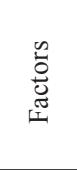 } & & & \multicolumn{3}{|c|}{$\begin{array}{l}\text { Time horizon of } \\
\text { impacts }\end{array}$} \\
\hline & & & $\begin{array}{c}0-5 \\
\text { years }\end{array}$ & $\begin{array}{l}5-10 \\
\text { years }\end{array}$ & $\begin{array}{c}10+ \\
\text { years }\end{array}$ \\
\hline \multirow{4}{*}{ 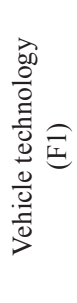 } & F11 & $\begin{array}{c}\text { Decrease of vehicle } \\
\text { production cost }\end{array}$ & & - & - \\
\hline & F12 & $\begin{array}{l}\text { Improvement of energy } \\
\text { efficiency and utilization }\end{array}$ & & & • \\
\hline & F13 & Development of batteries & & $\bullet$ & • \\
\hline & F14 & $\begin{array}{l}\text { Further development of } \\
\text { technical parameters }\end{array}$ & • & & \\
\hline \multirow{5}{*}{ 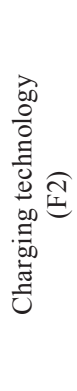 } & F21 & $\begin{array}{l}\text { Higher density of charging } \\
\text { stations }\end{array}$ & $\bullet$ & & \\
\hline & F22 & Increase of charging capacity & & $\bullet$ & • \\
\hline & F23 & $\begin{array}{l}\text { Innovative charging } \\
\text { technologies }\end{array}$ & & & • \\
\hline & $\mathrm{F} 24$ & $\begin{array}{l}\text { Spread of smart grid } \\
\text { technology }\end{array}$ & & & $\bullet$ \\
\hline & F25 & $\begin{array}{l}\text { Cleaner electricity } \\
\text { production }\end{array}$ & & & $\bullet$ \\
\hline \multirow{5}{*}{ 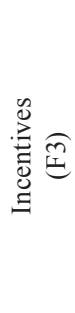 } & F31 & Purchase subsidies & • & & \\
\hline & F32 & Incentives to facilitate the use & • & & \\
\hline & F33 & $\begin{array}{l}\text { Incentives to support } \\
\text { installation of chargers }\end{array}$ & - & & \\
\hline & F34 & $\begin{array}{l}\text { Incentives to facilitate } \\
\text { operation of chargers }\end{array}$ & • & $\bullet$ & \\
\hline & F35 & Other, indirect incentives & & - & • \\
\hline
\end{tabular}

Table 2 Estimated average range of BEVs in Hungary

\begin{tabular}{lccc}
\hline Years & 2020 & 2025 & 2030 \\
\hline BEV range $[\mathrm{km}]$ & 200 & 300 & 405 \\
\hline
\end{tabular}

average future range of EVs in Hungary has been estimated in Table 2, considering the composition of the EV stock and the development trends. Around 2030, a steeper market surge of new models is expected.

Development of batteries requires higher charging capacity. 100-250 kW charging power will be applied at fast charging stations within a few years. These trends incite prescient development in the field of electricity network. Innovative solutions (e.g. superfast chargers, inductive chargers) may significantly change the operation.

Beyond technological development, governmental measures are also shaping user demand. Other, indirect incentives like supporting of research and development or shaping attitudes may have a positive effect on vehicle purchase and usage, as well as on installation and operation of charging stations.
Table 3 Charging demand characteristics at different location types

\begin{tabular}{lcc}
\hline Location type & $\begin{array}{c}\text { Frequency of } \\
\text { charging } \\
\text { [session/day/vehicle] }\end{array}$ & $\begin{array}{c}\text { Duration of } \\
\text { a charging } \\
\text { session[h:mm] }\end{array}$ \\
\hline Home & 0.72 & $5: 58$ \\
$\begin{array}{l}\text { Public places } \\
\text { (close to residence) }\end{array}$ & 0.27 & $1: 50$ \\
$\begin{array}{l}\text { Workplace } \\
\begin{array}{l}\text { Parking lots of stores, } \\
\text { markets }\end{array}\end{array}$ & 0.59 & $4: 44$ \\
$\begin{array}{l}\text { Parking lots near public } \\
\text { offices (post office, bank) }\end{array}$ & 0.18 & $0: 43$ \\
$\begin{array}{l}\text { P+R car parks } \\
\text { Parking lots at bus and train } \\
\text { stations }\end{array}$ & 0.09 & $0: 21$ \\
$\begin{array}{l}\text { Gas stations } \\
\text { Touristic, cultural and sport } \\
\text { facilities }\end{array}$ & 0.15 & $2: 09$ \\
\hline
\end{tabular}

\subsection{User requirements}

The user requirements have been revealed by online survey. The following topics have been addressed:

- driving patterns;

- charging patterns as well as expectations related to the charging session and infrastructure.

The questionnaire has been responded by 478 current or potential e-vehicle users in Hungary. The most important findings of the survey were as follows:

Driving patterns:

- average daily mileage is $40.2 \mathrm{~km}$;

- share of drivers who travel more than $100 \mathrm{~km}$ per day at least few times a year: $37 \%$.

The driving patterns clearly show that electromobility is a real alternative for a remarkable share of drivers. It is especially true, if they have opportunity to charge their vehicle at home (or close to home), or at their workplace.

Charging patterns as well as expectations related to the charging session and infrastructure are as follows:

- share of drivers who currently do not have any charging opportunities at home/at workplace/at public places close to their residence is rather high, $28.2 \%$;

- frequency and duration of charging sessions at different location types are presented in Table 3;

- acceptable charging time at public superfast chargers is $\sim 15$ mins;

- WIFI, lavatory, (fast) restaurants and shopping facilities for daily needs are the most required services near the charging stations. 
My survey concluded in similar results as the Estonian example: drivers prefer charging at home and at workplaces. In the future, 'fueling' the car should be considered as a routine being integrated in the daily activity chain, rather than a separated process.

\section{Calculation method and data}

The calculation method has been established with a modular structure having 5 modules (Fig. 1). Most of the modules contain several calculation processes. The first number of a calculation process refers to the module. The parameters and their calculation method are summarized in Table 4. The last column shows the calculation process wherein the input parameters are used, or the calculated data are produced. A calculation process uses either 'raw' input data from databases or 'calculated' input data from other calculation processes. The data flows are indicated by arrows.

In the fifth module, the calculated charging demand is to be assigned to the charging infrastructure to determine the capacity utilization.

Notations are as follows:

$(t)$ notation of time dependency (referring to the time interval of the investigation);

$i$ index of plug-in vehicle type: BEV, PHEV or REEV;

$j$ index of transport type: regional (r) or long-distance (ld) transport;

$k$ index of charger type: normal $(n)$, fast $(f)$ or superfast $(s f)$ charger.

The main advantages of the method are as follows:

- modular structure (the method produces useful partial results);

- applicable for any type of e-vehicles or vehicle fleets;

- adaptable for any territorial unit (spatial flexibility);

- adaptable for any time horizon (temporal flexibility).

Determination of input parameters is often a complex, difficult task. The data related to vehicles and charging infrastructure can be available from different sources (e.g. manufacturers, map databases); however, the user-related attributes (covered distance, preferences, etc.) can be collected through expensive measurements, surveys or estimations. The required input data have been categorized and assigned to databases as follows:

$\alpha$ : vehicle - data about size and composition of vehicle stock along with technical parameters;

$\beta$ : covered distance - data about the distance and share of mileage of plug-in EVs;

$\gamma$ : user preferences - data about the individual or collective charging habits and expectations;

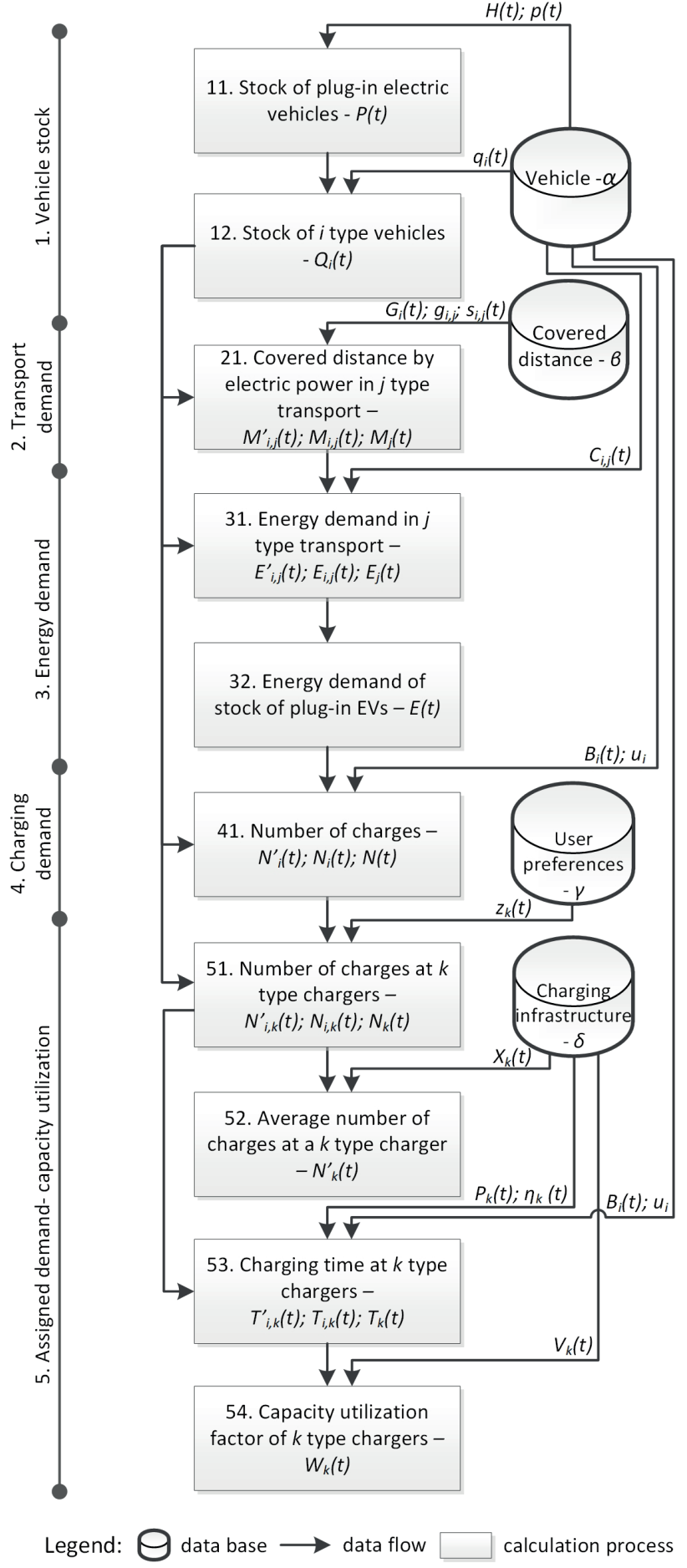

Fig. 1 Calculation method of EV charging demand

$\delta$ : charging infrastructure - data about size and composition of charging network, technical parameters of chargers.

When determining the value of a parameter, adjustment may be necessary to the implementation purpose (i.e. specialities of the area, time horizon, etc. are to be considered). For instance, different data are needed when 
Table 4 Parameters and their calculation method

\begin{tabular}{|c|c|c|c|c|}
\hline Notation & Meaning of parameter & Calculation method & Unit & Calculation process \\
\hline$H(t)$ & stock of passenger cars & & {$[\mathrm{pcs}]$} & 11 \\
\hline$p(t)$ & share of plug-in EVs in total passenger car stock & & - & 11 \\
\hline$P(t)$ & stock of plug-in EVs & $P(t)=H(t) \cdot p(t)$ & {$[\mathrm{pcs}]$} & 11 \\
\hline$q_{i}(t)$ & ratio of $i$ type vehicles in plug-in EVS & & - & 12 \\
\hline$Q_{i}(t)$ & stock of i type vehicles & $Q_{i}(t)=P(t) \cdot q_{i}(t)$ & {$[\mathrm{pcs}]$} & 12 \\
\hline$G_{i}(t)$ & covered distance of i type vehicles & & {$[\mathrm{km}]$} & 21 \\
\hline$g_{i, j}$ & share of covered distance of $i$ type vehicles in $j$ type transport & & - & 21 \\
\hline $\mathrm{s}_{i, j}(t)$ & share of electric drive of $i$ type vehicles in $j$ type transport & & - & 21 \\
\hline$M_{i, j}^{\prime}(t)$ & $\begin{array}{l}\text { covered distance by electric power of an i type vehicle in } \mathrm{j} \\
\text { type transport }\end{array}$ & $M_{i, j}^{\prime}(t)=G(t) \cdot g_{j} \cdot s_{i, j}$ & {$[\mathrm{~km}]$} & 21 \\
\hline$M_{i, j}(t)$ & $\begin{array}{l}\text { covered distance by electric power of stock of } i \text { type vehicles } \\
\text { in } j \text { type transport }\end{array}$ & $M_{i, j}(t)=M_{i, j}^{\prime}(t) \cdot Q_{i}(t)$ & {$[\mathrm{veh}-\mathrm{km}]$} & 21 \\
\hline$M_{j}(t)$ & $\begin{array}{l}\text { covered distance by electric power of stock of plug-in EVs in } \\
\text { j type transport }\end{array}$ & $M_{j}(t)=\sum_{i} M_{i, j}(t)$ & {$[\mathrm{veh}-\mathrm{km}]$} & 21 \\
\hline$C_{i, j}(t)$ & $\begin{array}{c}\text { average energy consumption of } i \text { type vehicles in j type } \\
\text { transport }\end{array}$ & & {$[\mathrm{kWh} / \mathrm{km}]$} & 31 \\
\hline$E_{i, j}^{\prime}(t)$ & energy demand of an i type vehicle in $\mathrm{j}$ type transport & $E_{i, j}^{\prime}(t)=M_{i, j}^{\prime}(t) \cdot C_{i, j}(t)$ & {$[\mathrm{kWh}]$} & 31 \\
\hline$E_{i, j}(t)$ & energy demand of stock of $i$ type vehicles in $\mathrm{j}$ type transport & $E_{i, j}(t)=E_{i, j}^{\prime}(t) \cdot Q_{i}(t)$ & {$[\mathrm{kWh}]$} & 31 \\
\hline$E_{j}(t)$ & energy demand of stock of plug-in EVs in $\mathrm{j}$ type transport & $E_{j}(t)=\sum_{i} E_{i, j}(t)$ & {$[\mathrm{kWh}]$} & 31 \\
\hline$E(t)$ & energy demand of stock of plug-in EVs & $E(t)=\sum_{j} E_{j}(t)$ & {$[\mathrm{kWh}]$} & 32 \\
\hline$B_{i}(t)$ & average capacity of the battery of $i$ type vehicles & & {$[\mathrm{kWh}]$} & 41,53 \\
\hline$u_{i}$ & average battery capacity utilization factor of $i$ type vehicles & & - & 41,53 \\
\hline$N_{i}^{\prime}(t)$ & number of charges of an i type vehicle & $N_{i}^{\prime}(t)=\frac{\sum_{j} E_{i, j}^{\prime}(t)}{B_{i}(t) \cdot u_{i}}$ & - & 41 \\
\hline$N_{i}(t)$ & number of charges of stock of i type vehicles & $N_{i}(t)=N_{i}^{\prime}(t) \cdot Q_{i}(t)$ & - & 41 \\
\hline$N(t)$ & number of charges of stock of plug-in EVs & $N(t)=\sum_{i} N_{i}(t)$ & - & 41 \\
\hline $\mathrm{z}_{k}(t)$ & share of charges at $k$ type chargers & & - & 51 \\
\hline$N_{i, k}^{\prime}(t)$ & number of charges of an i type vehicle at $k$ type chargers & $N_{i, k}^{\prime}(t)=N_{i}^{\prime}(t) \cdot z_{k}(t)$ & & 51 \\
\hline$N_{i, k}(t)$ & $\begin{array}{c}\text { number of charges of stock of } i \text { type vehicles at } k \text { type } \\
\text { chargers }\end{array}$ & $N_{i, k}(t)=N_{i, k}^{\prime}(t) \cdot Q_{i}(t)$ & & 51 \\
\hline$N_{k}(t)$ & number of charges of stock of plug-in EVs at k type chargers & $N_{k}(t)=\sum_{i} N_{i, k}(t)$ & - & 51 \\
\hline$X_{k}(t)$ & number of $k$ type chargers & & {$[\mathrm{pcs}]$} & 52 \\
\hline$N_{k}^{\prime}(t)$ & average number of charges at a $\mathrm{k}$ type charger & $N_{k}^{\prime}(t)=\frac{N_{k}(t)}{X_{k}(t)}$ & - & 52 \\
\hline$P_{k}(t)$ & average charging power of $k$ type chargers at the time $t$ & & {$[\mathrm{~kW}]$} & 53 \\
\hline$\eta_{k}(t)$ & average efficiency of charging at $k$ type chargers & & - & 53 \\
\hline$T_{i, k}^{\prime}(t)$ & average charging time of an i type vehicle at $\mathrm{k}$ type chargers & $T_{i, k}^{\prime}(t)=\frac{B_{i}(t) \cdot u_{i}}{P_{k}(t) \cdot \eta_{k}(t)}$ & {$[\mathrm{h}]$} & 53 \\
\hline$T_{i, k}(t)$ & charging time of stock of $\mathrm{i}$ type vehicles at $\mathrm{k}$ type chargers & $T_{i, k}(t)=T_{i, k}^{\prime}(t) \cdot N_{i, k}(t)$ & {$[\mathrm{h}]$} & 53 \\
\hline$T_{k}(t)$ & charging time of stock of plug-in EVs at $k$ type chargers & $T_{k}(t)=\sum_{i} T_{i, k}(t)$ & {$[\mathrm{h}]$} & 53 \\
\hline$V_{k}(t)$ & average availability time-base of $k$ type chargers & & {$[\mathrm{h}]$} & 54 \\
\hline$W_{k}(t)$ & capacity utilization factor of $\mathrm{k}$ type chargers & $W_{k}(t)=\frac{T_{k}(t)}{V_{k}(t)}$ & - & 54 \\
\hline
\end{tabular}


calculating the future energy demand and required number of chargers at national or regional level. Similarly, different technical parameters must be considered when calculating the charging demand for the short term (1-2 years or less) or the long term (10-15 years).

The modules can be calibrated and validated separately. The reliability of complex estimation tasks is significantly improved if the parameters are estimated separately and then they are involved in the complex calculation. For instance, calculation of future number of BEVs in module 1 is rather challenging, but the entire EV stock and the share of BEVs can be estimated separately with high reliability and then their multiplication provides the number of BEVs.

As the calculations can be performed even on a single vehicle, not only the technical parameters of different $\mathrm{EV}$ types (BEV/PHEV/REEV), but also parameters of a specific EV (e.g. Nissan Leaf) can be used as input data.

The charging demand can be calculated at local, regional or national level and it can be assigned to the charger types.

More detailed distribution of demand (e.g. in time) requires additional studies. For this purpose, data from empirical examinations can be also applied [31].

Most of the parameters are considered as time-dependent ones. Thus, the method is applicable for any time interval, with arbitrary starting time, and therefore modelers can take the technological, economic and social effects (e.g. increasing capacity of batteries, changes in transport habits) into account.

Collection of reliable input data is often a complex, challenging task. It may have several reasons: e.g. manufacturers do not provide data because of their business interests; accurate assessment of user preferences is expensive; or geospatial data are not available in the required structure. Another challenge is that there are no exact methodologies to determine the future technological trends; but, on the other hand, the calculation of demand requires the knowledge or estimation of several future parameters. Besides, revealing the patterns and needs of current and potential EV users is also essential to plan well-grounded services adjusted to users' demand.

\section{Application of the calculation method}

To demonstrate the applicability of the developed method, an example calculation is presented. Suppose a company, which plans to purchase an EV fleet containing 5 BEVs and 5 PHEVs. They are going to deploy and operate an own charging infrastructure for their EVs. Accordingly, they need to determine the charging demand of the vehicle fleet, considering the company's operational conditions. The operational attributes are taken in a weekly timeframe. They are looking for the answers to the following questions:

1. How much energy is required for operating the different types of EVs and the entire fleet on a weekly basis?

2. How many times should the different types of EVs be charged on a weekly basis?

3. What are the average charging times of the different types of EVs at the different charger types?

4. How long does it take to meet the weekly energy demand of the entire fleet at the different charger types?

The input parameters are summarized and presented according to the introduced databases in Table 5. Note that the company does not know the number of the chargers to be deployed in advance, as they are going to determine that by the calculation. Therefore, data about the user preferences related to the charging sessions ( $\gamma$ database, $z_{k}$ value), and the size of the charging infrastructure ( $X_{k}$ value) have not been considered in the example at this point.

Table 5 Input parameters of the example calculation

\begin{tabular}{|c|c|c|c|c|c|c|c|c|c|c|}
\hline Data-base & & & & & $\alpha$ (vehicle) & & & & & \\
\hline Data & $Q_{B E V}$ & $Q_{\text {PHEV }}$ & $C_{B E V, r}$ & $C_{B E V, l d}$ & $C_{P H E V, r}$ & $C_{\text {PHEV,Id }}$ & $B_{B E V}$ & $B_{\text {PHEV }}$ & $u_{B E V}$ & $u_{P H E V}$ \\
\hline Value & 5 & 5 & 17.2 & 19.1 & 23 & 24.9 & 30 & 8.8 & 0.8 & 1 \\
\hline Unit & pcs & pcs & $\mathrm{kWh} / 100 \mathrm{~km}$ & $\mathrm{kWh} / 100 \mathrm{~km}$ & $\mathrm{kWh} / 100 \mathrm{~km}$ & $\mathrm{kWh} / 100 \mathrm{~km}$ & $\mathrm{kWh}$ & $\mathrm{kWh}$ & - & - \\
\hline Data-base & \multicolumn{10}{|c|}{$\beta$ (covered distance) } \\
\hline Data & $G_{B E V}$ & $G_{\text {PHEV }}$ & $g_{B E V, r}$ & $g_{B E V, I d}$ & $g_{P H E V, r}$ & $g_{P H E V, I d}$ & $S_{B E V, r}$ & $s_{B E V, l d}$ & $s_{P H E V, r}$ & $s_{P H E V, l d}$ \\
\hline Value & 700 & 600 & 0.9 & 0.1 & 0.2 & 0.8 & 1 & 1 & 0.8 & 0.25 \\
\hline Unit & $\mathrm{km} /$ week & $\mathrm{km} /$ week & - & - & - & - & - & - & - & - \\
\hline Data-base & \multicolumn{10}{|c|}{$\delta$ (charging infrastructure) } \\
\hline Data & $P_{n}$ & $P_{f}$ & $\eta_{n}$ & $\eta_{f}$ & $V_{n}$ & $V_{f}$ & & & & \\
\hline Value & 3.6 & 20 & 0.83 & 0.88 & 168 & 168 & & & & \\
\hline Unit & $\mathrm{kW}$ & $\mathrm{kW}$ & - & - & $\mathrm{h} /$ week & $\mathrm{h} /$ week & & & & \\
\hline
\end{tabular}


The data applied in the example are real-life values. The average energy consumption of the vehicles $\left(C_{i, j}\right)$ and capacity of the batteries $\left(B_{i}\right)$ are to be defined according to the type of EVs to be purchased. In the example, the data of a 2015 model Nissan Leaf BEV with $30 \mathrm{kWh}$ battery pack, and the data of Audi A3 e-tron PHEV are considered, using the experimental average fuel consumption data of EPA (United States Environmental Protection Agency - www. epa.gov/fueleconomy) for a combined city/highway use.

The average value of battery capacity utilization factor $\left(u_{i}\right)$ can be determined by the decision-maker based on the expected usage characteristics. In my example, value of 0.8 has been assumed for BEVs, while the value of 1 has been assigned for PHEVs as these vehicles are able to operate also when their batteries are exhausted. Based on the data, the company plans to use the BEVs mainly in regional transport $\left(g_{B E V, r}-90 \%\right)$ travelling a weekly average $700 \mathrm{~km}$ per vehicle $\left(G_{B E V}\right)$.

PHEVs are planned to be used mainly in long-distance transport $\left(g_{P H E V, l d}-80 \%\right)$, travelling a weekly average 600 $\mathrm{km}$ per vehicle $\left(G_{P H E V}\right)$. Besides, the company plans to reach a $25 \%$ share of electric drive in long-distance transport with their PHEVs $\left(s_{\text {PHEV,ld }}\right)$, and $80 \%$ share of electric drive in case of regional travels $\left(s_{P H E V, r}\right)$.

For charging infrastructure, they can install normal and/or fast chargers, with $3.6 \mathrm{~kW}\left(P_{n}\right)$, or $20 \mathrm{~kW}\left(P_{f}\right)$ charging power that are available non-stop $\left(V_{k}=168 \mathrm{~h} /\right.$ week). The average efficiency of charging at the different charger types $\left(\eta_{k}\right)$ have been determined based on scientific research [32], which has been supplemented by experimental data of current EV users [33].

The calculations have been performed based on the input parameters.

Module 1: The investigated vehicle stock is given in the example.

Module 2: Based on the data of the vehicle and covered distance, transport demand [veh-km] (covered distance by electric power) are calculated related to vehicle types and transport types.

Based on the specified input data, the following partial results have been obtained:

- $M_{B E V, r}=3150$ veh-km; $M_{B E V, l d}=350$ veh-km;

$M_{P H E V, r}=480$ veh-km; $M_{P H E V, l d}=600$ veh-km;

- $M_{r}=3630$ veh-km; $M_{l d}=950$ veh-km.

Module 3: The energy demand [kWh] is also to be calculated related to vehicle types and transport types. Partial results related to the EV fleet, answering the first question of the company:
- $E_{B E V, r}=541.8 \mathrm{kWh} ; E_{B E V, l d}=66.9 \mathrm{kWh}$;

$E_{\text {PHEV }, r}=110.4 \mathrm{kWh} ; E_{\text {PHEV }, l d}=149.4 \mathrm{kWh}$;

- $E_{r}=652.2 \mathrm{kWh} ; E_{l d}=216.3 \mathrm{kWh}$;

- $E=868.5 \mathrm{kWh}$.

Module 4: The charging demand (number of necessary charging sessions) is to be determined related to vehicle types (for one-week period). The following partial results have been obtained related to each vehicle, and for the entire fleet, answering the second question of the company:

- $N_{B E V}^{\prime}=5.1 ; N_{P H E V}^{\prime}=5.9$;

- $N_{B E V}=25.4 ; N_{\text {PHEV }}=29.5$.

Module 5: The aim in this module is to assign the calculated demand to the chargers. However, size and composition of the charging infrastructure are unknown in the presented example as the company would like to determine them based on the results of the calculation. For this purpose, the number of charging sessions solely does not provide enough input. Therefore, the average charging times regarding the vehicle types have been determined related to both charger types, based on the parameters of the considered chargers and vehicles. These values answer the third question of the company:

- $\mathrm{T}_{\mathrm{BEV}, \mathrm{n}}^{\prime}=8 \mathrm{~h} ; \mathrm{T}_{\mathrm{BEV}, \mathrm{f}}^{\prime}=1.4 \mathrm{~h}$;

- $\mathrm{T}_{\text {PHEV, } \mathrm{n}}^{\prime}=2.9 \mathrm{~h} ; \mathrm{T}_{\mathrm{PHEV}, \mathrm{f}}^{\prime}=0.5 \mathrm{~h}$.

In order to support the decision-making related to the charging infrastructure, the total charging time required to meet the weekly energy demand of the entire fleet has also been provided according to the different charger types. These values answer the fourth question of the company:

- $T_{B E V, n}^{\prime}=203.7 \mathrm{~h} ; T_{B E V, f}^{\prime}=34.6 \mathrm{~h}$;

- $T_{\text {PHEV }, n}^{\prime}=86.9 \mathrm{~h} ; T_{\text {PHEV }, f}^{\prime}=14.8 \mathrm{~h}$.

The calculated charging demand is to be considered as basic data for the determination of the size and composition of the charging infrastructure to be deployed and operated.

The exact number and type of chargers can be determined with consideration to further user preferences and the possibilities from the electric grid side. These aspects are still not included in the method, but I am going to extend my research activity towards this direction. Namely, my research will focus on the charging management strategies. Among others, the following issues are to be addressed:

- time distribution and length of travels made by EVs;

- duration and time distribution of vehicle staying at the company premises;

- connect and disconnect frequency of vehicles at the chargers (e.g. whether a person is available to do this task when a charging session is completed, even at night, etc.). 
Knowing the size $\left(X_{k}\right)$ and characteristics $\left(P_{k}, \eta_{k}, V_{k}\right)$ of the charging infrastructure, the capacity utilization of chargers can also be calculated according to the last elaborated formula ( $W_{k}$ - calculation process 54$)$.

The presented example proves the time flexibility of the method. Both the considered time interval and the time of examination are arbitrary. In my example, oneweek time interval and the current data have been used. Furthermore, it has also been proved that both the single vehicles (according to their type-specific data) and the vehicle fleets can be considered during the calculations.

Similarly, the elaborated calculation method is an effective support tool to solve various practical problems. For example, the energy and charging demand of a single EV can be calculated for a potential owner. In this way, the decision whether to buy an EV or not, and the operational planning (number and length of charging sessions, etc.) are supported.

At the same time, calculations for a fleet of vehicles, either on a regional or national level can be made, supporting the decisions of both policy makers and energy providers. For existing, or planned charging networks, the calculation method ensures the charging infrastructure to be evaluated (e.g. capacity utilization) or (re-) designed (e.g. number of charging sessions at different type of chargers based on the calculated energy demand and charging times).

\section{Public charging station locating principles}

The main application field of the presented method is to support the charging station deployment. The deployment is a complex task; it requires expertise from several fields: civil engineering, electrical and transportation engineering, economics, law, etc. The location of the charging station should meet the following requirements:

- location close to the charging demand derived from the travel behaviour and

- sufficient electric network capacity to serve the charging requirements, or the cost of capacity expansion is not significant.

Accordingly, electric network and transport network approaches can be distinguished. Without mass market adoption, the locations of the charging stations significantly influence the utilization.

Charging demand types are to be distinguished according to when and where the charging demand arises:

- Inter-city demand: during a long-distance journey.

- Intra-city demand: at the end of a short-distance trip.
The main difference between them is the motivation. In the case of a long-distance journey, the driver must break the travel to charge the vehicle. Thus, the motivation of inter-city demand is solely the charging. In the case of a short-distance trip, the vehicle can be charged at the end of a trip. Thus, the charging event contributes to the usefulness of parking. Different charging station locating approaches should be applied to the different charging demands.

\section{Geoinformatics applications for locating charging stations}

Several methods and applications have been developed for locating charging stations along national roads and in urban areas according to the given objective function. I present novel solutions to demonstrate the application opportunities of the demand calculation method. In the presented applications, geoinformatics data assigned to a territory unit, a section or a point are used with different aggregation levels at the same time.

\subsection{Locating superfast charging stations along national roads}

A point-oriented locating method using geoinformatics simulation and greedy algorithm can be applied for this purpose. An 'oil stain' deployment strategy is to be used to achieve even coverage with the minimum number of charging stations along the roads.

Several demographics, neighbourhood, and transportation-related attributes, as well as the available services that influence the charging station use can be identified and their effects can be revealed in a systematic approach. All the available datasets are georeferenced, therefore can be processed by geographic information systems (GIS).

The multi-criteria decision-making method is to be applied to evaluate the rest areas along national roads and propose deployment locations for charging stations. This approach is especially beneficial if the origin-destination flows are unknown. The even distribution of the stations contributes to the high utilization of the charging stations.

The existing rest areas that have different available services (e.g. restroom, restaurant, etc.) along national roads can be investigated, because the available services significantly influence the attractiveness of a charging station as they raise the utility of time spent during charging.

The installation potential for candidate sites can be calculated as a space-varying aggregated evaluation number. For this purpose, the stock of BEV vehicles $\left(Q_{B E V}\right)$ from 
module 1 and the covered distance by electric power in long-distance transport $\left(M_{l d}\right)$ from module 2 can be considered on nearby roads or in the affected territorial units. The effect of the nearest fast charging station is also significant, because it decreases the installation potential.

It can be assumed that the inter-city traffic is concentrated on the main national roads. Hence, the road categories are prioritized, and the selection of installation sites can be performed on two different layers. On the first layer the candidate sites along highways are considered, on the second layer along other national roads. A candidate site that is along several types of roads is considered on all layers. The installation requirements may differ for the two layers. According to this approach, the drivers are encouraged to use the high capacity roads for a long-distance journey.

A greedy algorithm considering the installation potential can be used to select the suitable candidate sites.

The following installation requirements can be introduced:

- number of charging stations to be deployed,

- length of covered roads,

- coverage efficiency of deployment when adding a new point.

\subsection{Locating urban public fast charging stations}

Recently, the land-use based applications gain ground in this field, as the drivers do not stop for charging in urban areas; the charging is a supplementary activity during parking. Accordingly, the parking habits and motivations can be considered through land use aspects. On the other hand, land-use data and geoinformatics data are more likely available than origin-destination data in small areas.

A charging station locating method can be applied for this purpose, where weighted sum values are introduced to evaluate territory segments and to allocate charging stations within a segment using a hexagon-based approach and greedy algorithm. In this way, adjusting the preferences to the decision makers' needs is also possible. Furthermore, large amount of data can be considered and the effects of hardly or non-quantifiable factors also can be incorporated. This method assesses the potential of EV use on macro-level and the possible locations of charging stations on micro-level.

The locations can be determined in two steps:

1. Distribution of charging stations among territory segments in the investigated territory considering the potential of EV use (macro evaluation).
2. Locating the charging stations for each territory segment on the base of parking behaviour according to land-use aspects (micro evaluation).

Different aims can be defined, and heterogeneous data types can be used on these levels. The evaluations can be performed separately, too.

On macro level, the following main parameters can be considered to calculate the installation potential of a territory segment: the stock of plug-in EVs $(P)$ and stock of BEV and PHEV vehicles $\left(Q_{B E V}, Q_{P H E V}\right)$ from module 1 and the covered distance by electric power in regional transport $\left(M_{r}\right)$ from module 2 . The potential of EV use may depend also on the average income per person and the relevancy of tourism.

On micro level, each territory segment can be divided into hexagons because they cover the segment without overlap and its shape is close to a circle. The distance between the parallel sides of a hexagon is recommended to be 250 meters because it is a widely accepted walking distance between the parking place and the destination. The charging stations are to be assigned to the most attractive hexagons. A hexagon is attractive if the number of charges at fast chargers $\left(N_{f}\right)$ from module 4 is high. Beyond the transport demand, several other aspects may influence the location of a charging station, such as the ownership of the spot and available capacity of the electric network. The energy demand $(E)$ can be calculated according to module 3 .

The public charging demand of a hexagon can also be calculated as the weighted sum of the daytime and nighttime charging demand. The daytime charging demand is to be derived from the destination types available in the hexagon (points of interest, services). The night-time charging demand is to be derived from the population and the residential area type of a hexagon. The willingness to walk should be also considered, which is the maximum distance that an EV user would walk between a charging station and her/his destination.

\section{Conclusions}

To support the wider spread of electromobility, the new challenges related to the operation must be tackled properly. Both the existing and the potential charging demand have to be determined to find the most appropriate locations for public charging stations.

The main contribution of the paper is the systematic overview of the parameters with their correlations and the comprehensive calculation method of EV charging demand. Accordingly, the method has a modular structure. 
All the relevant input data, the 'components' of the charging demand and aspects of charging station deployment have been identified and considered. Public charging station locating principles and novel geoinformatics application opportunities with unique approaches and models based on the method have been presented. The novelty of the method lies in its complexity and multi-purpose usability. It is applicable for any type of e-vehicles or vehicle fleets, adaptable for any territorial unit and flexible in time (according to the time-relevant data). Determination of the number of charging sessions, charging time and capacity utilization of chargers is also supported. Since all the source and derived data are georeferenced, the results can be visualized and presented in multiple geoinformation systems.

The most relevant application fields of the calculation method are:

- decision-making on different levels (national government, municipality, etc.),

- urban planning (considering parking and charging habits),

- development and operation of electromobility-related services (e.g. smart grid service, charging assistance),

- development of electricity network and supply.

Accordingly, my future research focuses on:

- expectations toward the charging infrastructure; especially the new charging technologies;

- construction and installation requirements of charging facilities;

- regulation framework of charging facilities.

\section{Acknowledgement}

The research reported in this paper was performed in the frame of Electric Travelling project. Electric Travelling project has received funding from European Union's Horizon 2020 research and innovation programme, on the basis of grant contract No. NGM_SZERZ/218/2018 concluded with the Ministry for National Economy of Hungary.

The research reported in this paper was supported by the Higher Education Excellence Program of the Ministry of Human Capacities in the frame of Artificial Intelligence research area of Budapest University of Technology and Economics (BME FIKP-MI/FM).

\section{References}

[1] Wang, D., Zamel, N., Jiao, K., Zhou, Y., Yu, S., Du, Q., Yin, Y. "Life cycle analysis of internal combustion engine, electric and fuel cell vehicles for China", Energy, 59, pp. 402-412, 2013. https://doi.org/10.1016/j.energy.2013.07.035
[2] Török, A. "Comparative analysis between the theories of road transport safety and emission", Transport, 32(2), pp. 192-197, 2017. https://doi.org/10.3846/16484142.2015.1062798

[3] European Commission "White Paper, Roadmap to a Single European Transport Area - Towards a competitive and resource efficient transport system", [pdf] COM, Brussels, Available at: http://eur-lex.europa. eu/LexUriServ/LexUriServ.do?uri=COM:2011:0144:FIN:en:PDF [Accessed: 06.08.2018]

[4] Muneer, T., Milligan, R., Smith, I., Doyle, A., Pozuelo, M., Knez, M. "Energetic, environmental and economic performance of electric vehicles: experimental evaluation", Transportation Research Part D: Transport and Environment, 35, pp. 40-61, 2015. https://doi.org/10.1016/j.trd.2014.11.015

[5] Skrucany T., Harantova, V., Kendra, M., Barta, D. "Reducing energy consumption by passenger car with using of non-electrical hybrid drive technology", Advances in Science and Technology Research Journal, 11(1), pp. 166-172, 2017. https://doi.org/10.12913/22998624/66505

[6] Szauter, F., Péter, T., Lakatos, I. "Examinations of complex traffic dynamic systems and new analysis, modeling and simulation of electrical vehicular systems", presented at: MESA 2014 - 10th IEEE/ ASME International Conference on Mechatronic and Embedded Systems and Applications, Senigallia, Italy, September, 10-12, 2014.

https://doi.org/10.1109/MESA.2014.6935613

[7] Tettamanti, T., Varga, I., Szalay, Zs. "Impacts of Autonomous Cars from a Traffic Engineering Perspective", Periodica Polytechnica Transportation Engineering, 44(4), pp. 244-250, 2016. https://doi.org/10.3311/PPtr.9464

[8] Török, Á., Pauer, G. "Assessment of the Current Status of Intelligent Transport Systems Serving the Improvement of Road Safety in Hungary", Periodica Polytechnica Transportation Engineering, 45(2), pp. 77-83, 2017. https://doi.org/10.3311/PPtr.9279

[9] International Energy Agency "Global EV Outlook 2016- Beyond one million electric cars", [pdf] Available at: https://www.iea.org/publications/freepublications/publication/Global_EV_Outlook_2016.pdf [Accessed: 06.08.2018].

[10] Sierzchula, W., Bakker, S., Maat, K., van Wee, B. "The influence of financial incentives and other socio-economic factors on electric vehicle adoption", Energy Policy, 68, pp. 183-194, 2014. https://doi.org/10.1016/j.enpol.2014.01.043

[11] Matthews, L., Lynes, J., Riemer, M., Del Matto, T., Cloet, N. "Do we have a car for you? Encouraging the uptake of electric vehicles at point of sale", Energy Policy, 100, pp. 79-88, 2017. https://doi.org/10.1016/j.enpol.2016.10.001

[12] Přibyl, O., Svítek, M. "System-oriented Approach to Smart Cities", presented at: 2015 IEEE First International Smart Cities Conference (ISC2), Guadalajara, Mexico, October, 25-28, 2015. https://doi.org/10.1109/ISC2.2015.7428760

[13] Fink, H., Rees, S., Fetzer, J. "Generation 2 Lithium-Ion battery systems - Technology trends and KPIs", In: 15th Stuttgart International Symposium: Automotive and Engine Technology, Stuttgart, Germany, 2015, pp. 571-579. https://doi.org/10.1007/978-3-658-08844-6_37 
[14] Schönknecht, A., Babik, A., Rill, V. "Electric Powertrain System Design of BEV and HEV Applying a Multi Objective Optimization Methodology", Transportation Research Procedia, 14, pp. 36113620, 2016.

https://doi.org/10.1016/j.trpro.2016.05.429

[15] Bubeck, S., Tomaschek, J., Fahl, U. "Perspectives of electric mobility: Total cost of ownership of electric vehicles in Germany", Transport Policy, 50, pp. 63-77, 2016. https://doi.org/10.1016/j.tranpol.2016.05.012

[16] Hagman, J., Ritzén, S., Stier, J. J., Susilo, Y. "Total cost of ownership and its potential implications for battery electric vehicle diffusion", Research in Transportation Business \& Management, 18, pp. 11-17, 2016.

https://doi.org/10.1016/j.rtbm.2016.01.003

[17] Prud'homme, R., Koning, M. "Electric vehicles: A tentative economic and environmental evaluation", Transport Policy, 23, pp. 60-69, 2012.

https://doi.org/10.1016/j.tranpol.2012.06.001

[18] Fontaínhas, J., Cunha, J., Ferreira, P. "Is investing in an electric car worthwhile from a consumers' perspective", Energy, 115(2), pp. 1459-1477, 2016.

https://doi.org/10.1016/j.energy.2016.05.075

[19] Altan, M. F., Ayözen, Y. E. "The Effect of the Size of Traffic Analysis Zones on the Quality of Transport Demand Forecasts and Travel Assignments", Periodica Polytechnica Civil Engineering, 62(4) 971-979, 2018. https://doi.org/10.3311/PPci.11885

[20] Bocz, P., Kisgyörgy, L., Vasvári, G. "Etraffic - an Open Access Transportation Model", Periodica Polytechnica Civil Engineering, 61(3), pp. 564-568, 2017. https://doi.org/10.3311/PPci.9355

[21] Drovtar, I., Rosin, A., Landsberg, M., Kilter, J. "Large scale electric vehicle integration and its impact on the Estonian power system", presented at: 2013 IEEE Grenoble Conference (PowerTech), Grenoble, France, June, 16-20, 2013. https://doi.org/10.1109/PTC.2013.6652181

[22] Joller, L., Varblane, U. "Learning from an electromobility living lab: Experiences from the Estonian ELMO programme", Case Studies on Transport Policy, 4(2), pp. 57-67, 2016. https://doi.org/10.1016/j.cstp.2015.11.001

[23] De Gennaro, M., Paffumi, E., Martini, G. "Customer-driven design of the recharge infrastructure and Vehicle-to- Grid in urban areas: A large-scale application for electric vehicles deployment", Energy, 82, pp. 294-311, 2015.

https://doi.org/10.1016/j.energy.2015.01.039

[24] Cai, H., Jia, X., Chiu, A. S. F., Hu, X., Xu, M. "Siting public electric vehicle charging stations in Beijing using big-data informed travel patterns of the taxi fleet", Transportation Research Part D: Transport and Environment, 33, pp. 39-46, 2014.

https://doi.org/10.1016/j.trd.2014.09.003

[25] Shahraki, N., Cai, H., Turkay, M., Xu, M. "Optimal locations of electric public charging stations using real world vehicle travel patterns", Transportation Research Part D: Transport and Environment, 41, pp. 165-176, 2015. https://doi.org/10.1016/j.trd.2015.09.011
[26] Namdeo, A., Tiwary, A., Dziurla, R. "Spatial planning of public charging points using multi-dimensional analysis of early adopters of electric vehicles for a city region", Technological Forecasting and Social Change, 89, pp. 188-200, 2014. https://doi.org/10.1016/j.techfore.2013.08.032

[27] Xi, X., Sioshansi, R., Marano, V. "Simulation-optimization model for location of a public electric vehicle charging infrastructure", Transportation Research Part D: Transport and Environment, 22, pp. 60-69, 2013. https://doi.org/10.1016/j.trd.2013.02.014

[28] Sathaye, N., Kelley, S. "An approach for the optimal planning of electric vehicle infrastructure for highway corridors", Transportation Research Part E: Logistics and Transportation Review, 59, pp. 15-33, 2013. https://doi.org/10.1016/j.tre.2013.08.003

[29] Xydas, E., Marmaras, C., Cipcigan, L. M., Jenkins, N., Carroll, S., Barker, M. "A data-driven approach for characterising the charging demand of electric vehicles: A UK case study", Applied Energy, 162, pp. 763-771, 2016. https://doi.org/10.1016/j.apenergy.2015.10.151

[30] Mruzek, M., Gajdáč, I., Kučera, L., Gajdošík, T. "The Possibilities of Increasing the Electric Vehicle Range", Procedia Engineering, 192, pp. 621-625, 2017. https://doi.org/10.1016/j.proeng.2017.06.107

[31] Schäuble, J., Kaschub, T., Ensslen, A., Jochem, P., Fichtner, W. "Generating electric vehicle load profiles from empirical data of three EV fleets in Southwest Germany", Journal of Cleaner Production, 150, pp. 253-266, 2017. https://doi.org/10.1016/j.jclepro.2017.02.150

[32] Apostolaki-Iosifidou, E., Codani, P., Kempton, W. "Measurement of power loss during electric vehicle charging and discharging", Energy, 127, pp. 730-742, 2017. https://doi.org/10.1016/j.energy.2017.03.015

[33] Tesla Living "Measuring EV charging efficiency", [online] Available at: http://teslaliving.net/2014/07/07/measuring-ev-charging-efficiency/[Accessed: 06.08.2018] 